\title{
An evaluation of the impact of a restrictive retail food environment intervention in a rural community pharmacy setting
}

\author{
Leia M. Minaker ${ }^{1 *}$, Dana Lee Olstad², Graham MacKenzie ${ }^{3}$, Nghia Nguyen$^{1}$, Sunday Azagba', Brian E. Cook ${ }^{4}$
} and Catherine L. Mah ${ }^{5}$

\begin{abstract}
Background: Sugar-sweetened beverage consumption is associated with morbidity and mortality. The retail food environment influences food and beverage purchasing and consumption. This study assesses the impact of a community pharmacy's removal of sweet beverages on overall community sales of carbonated soft drinks (CSD) in a rural setting. We also examined whether the pharmacy intervention affected CSD sales in the town's other food stores.

Methods: Weekly CSD sales data were acquired from the three food retailers in the town of Baddeck, Nova Scotia (January 1, 2013 to May 8, 2015, n= 123 weeks). Autoregressive integrated moving average (ARIMA) analysis was used to analyse the interrupted time series data and estimate the impact of the pharmacy intervention (September 11, 2014) on overall CSD sales at the community level. Data were analysed in 2015.

Results: Before the intervention, the pharmacy accounted for approximately $6 \%$ of CSD sales in the community. After the intervention, declines in total weekly average community CSD sales were not statistically significantly. CSD sales at the other food stores did not increase after the pharmacy intervention.

Conclusions: This study was among the first to examine the impact of a restrictive retail food environment intervention, and found a non-significant decline in CSD sales at the community level. It is the first study to examine a retail food environment intervention in a community pharmacy. Pharmacies may have an important role to play in creating healthy retail food environments.
\end{abstract}

\section{Background}

Excess sugar consumption has been linked to weight gain, obesity, type 2 diabetes, and cardio-vascular risk factors [1-3]. Globally, sugar-sweetened beverage consumption accounts for approximately 184,000 deaths annually [4]. New WHO guidelines recommend adults and children consume less than $10 \%$ of their total energy intake as free sugars, and encourage a further reduction to below $5 \%$ (about $25 \mathrm{~g}$ or 6 teaspoons) for additional health benefits [5]. To contextualize this amount, one $355 \mathrm{~mL}$ can of Coca-Cola contains $39 \mathrm{~g}$ (about 10

\footnotetext{
* Correspondence: Iminaker@uwaterloo.ca

${ }^{1}$ Propel Centre for Population Health Impact, Faculty of Applied Health Sciences, University of Waterloo, 200 University Avenue West, Waterloo, ON N2L 3G1, Canada

Full list of author information is available at the end of the article
}

teaspoons of sugar), approximately $8 \%$ of the daily energy requirement for an individual [6].

Food consumption and its downstream effects on health are constrained and embedded within individuals' social, economic, and physical environments [7-11]. Food environments facilitate access to unhealthy foods by exploiting individuals' biological, psychological, social, and economic vulnerabilities [12]. Over 70 cents of every household food dollar is spent in stores (as opposed to restaurants) [13]. Retail food environment (RFE) interventions are interventions in food stores and restaurants that aim to support healthier dietary behaviours by improving access to and availability of affordable, healthier food options in the community and consumer nutrition environments [14]. Examples include zoning regulations to restrict fast food outlets from opening in neighbourhoods, [15] 'healthy corner store' programs, [16] and 
point-of-purchase information in grocery stores [17]. Kremers notes that energy-balance related behaviours (such as sugar consumption) can be governed by environmental cues through automatic environment-behavior links rather than through individuals' conscious processing and deliberate choices [18]. Retail food environment interventions thus aim to shift environmental cues towards health-promoting dietary intake, and away from disease-promoting dietary intake.

Existing RFE interventions have typically been permissive in nature, rather than restrictive. Permissive interventions nudge consumers towards healthier food purchasing by promoting availability of affordable, nutrient-dense foods. Conversely, restrictive interventions aim to decrease availability of calorie-dense, nutrient-poor foods. Restrictive interventions are less well represented in the literature $[16,19]$.

This study examines an intriguing example of a recent retailer-led restrictive RFE intervention in the province of Nova Scotia, Canada. In September 2014, a pharmacist made national and regional news by removing all sweet beverages from his pharmacy's shelves [20, 21]. When questioned about his objectives, the pharmacist commented, "It made no sense to me. Just in good conscience, we just couldn't continue selling" [20]. This retailer-led action constituted an excellent opportunity to conduct a natural experiment to evaluate the impact of a restrictive intervention. The objective of this study was to assess the effect of restricting availability of unhealthy beverage options in the pharmacy on sales of carbonated soft drinks (CSD) at the community level. We also examined whether there was any evidence of "switching" behaviour among stores in the town. That is, did removal of CSD from the pharmacy affect sales of CSD in the other Baddeck food stores? Given that many CSD purchases represent impulsive decisions, [22] we hypothesized that CSD sales would not increase at the other food stores in Baddeck, and that there would be an overall net decline in CSD sales.

\section{Methods}

\section{Context}

Baddeck is a rural small town (population approximately 800 year-round residents) on Cape Breton Island in Nova Scotia. Baddeck is a popular tourist destination in the summer months, and throughout the year functions as a service center for the surrounding, sparsely populated county. The nearest urban municipality is Sydney, Nova Scotia (population 31,597), $80 \mathrm{~km}$ away (about an hour's drive). The community nutrition environment in Baddeck includes twelve restaurants (several of which are only open seasonally), and three food stores including the pharmacy. In September 2014, the owner of the pharmacy pulled all sugar- and artificially-sweetened beverages from his shelves but continued to sell milk and water. The pharmacist's decision to stop selling these beverages made national and regional news $[20,21,23]$.

\section{Data sources}

Weekly sales data on sweet beverages were requested from all three retail food stores in Baddeck. Store 1 and Store 2 consented to provide detailed CSD but not other sweet beverage data, such as juice. Therefore, although the pharmacy ban encompassed all sweet beverages, our study analyzes only sales of CSD (including diet and regular varieties). For the purpose of this study, CSD are considered sweetened drinks that contain carbonated water (including artificially sweetened drinks as well as drinks sweetened with sugar or fruit juice). Weekly sales (in Canadian dollars) of CSD were acquired from the three food stores in Baddeck from January 1, 2013 (the earliest date data were readily available) to May 8, 2015 (the date data were requested) ( $n=123$ weeks). CSD sales peaked in June, July and August, consistent with Canadian data on seasonality of CSD sales [22]. Weeks were categorized in a dichotomous summer peak variable, where weeks in June, July and August were coded as summer peak weeks. Weeks were also categorized as pre-intervention (between January 1, 2013 and September 11, 2014, which was the date that the sweet beverages were pulled from shelves; $n=88$ weeks) and post-intervention (September 11, 2014 to May 8, 2015; $n=35$ weeks).

\section{Statistical analysis}

Descriptive statistics were used to examine the mean weekly sales and $95 \%$ confidence interval of the mean for pre-intervention and post-intervention periods, as well as for summer peak weeks and non-peak weeks. Preliminary t-tests were run to determine whether mean weekly sales differed significantly by intervention presence (pre/post) and by peak versus non-peak sale weeks (yes/no).

Although several analytical options exist to analyse time series data, [24] our interrupted time series data were most appropriately analysed using autoregressive integrated moving average (ARIMA) models. These models attempt to account for all aspects of data series autocorrelation, and are appropriate for repeated measures data assessed at equal intervals. We employed a systematic process for each ARIMA model using three standard procedures: model identification, parameter estimation, and diagnostic checking. We fit and compared various ARIMA models, including autoregressive, moving average, or autoregressive moving average models. The simplest model that best described the behaviour of 
the time series was selected. Differencing (i.e., calculating differences among pairs of observations at some time lag) was used to achieve stationarity. Detailed model specifications are available upon request. Briefly, the time-series data were highly auto-correlated. Data were differenced once to achieve stationarity. Adequacy of all candidate models were assessed visually with autocorrelation function and partial autocorrelation function plots, Ljung-Box chi-square tests for normally distributed white noise residuals, and Q-Q plots and normal distribution histograms of residuals. Finally, Akaike's information criteria (AIC) and Bayesian information criterion (BIC) were used to establish model fit.

We present two final ARIMA 110 models (for $\mathrm{AR}=1$, diff $=1$ and $\mathrm{MA}=0$ ) for the community as a whole, which represent the sum of all three stores' weekly CSD sales. Final models converged well and were adequate as determined by the diagnostic tests noted above. The first ARIMA model included the variables week number, policy, and summer peak. The second ARIMA model included the variables week number, policy, and seasonality as defined by the ARIMA procedure.

To assess switching behaviour, we also created two ARIMA 110 models (for $\mathrm{AR}=1$, diff $=1$ and $\mathrm{MA}=0$ ) for Store 1 and Store 2 individually. If consumers who purchased CSD from the pharmacy switched to Store 1 or Store 2 after the policy to purchase CSD, we would expect to see increases in CSD sales in those stores. Statistical significance was considered $p<0.05$. Analyses were performed using PROC ARIMA in SAS V.9.3.

Institutional research ethics board approval was not sought for this study as it did not involve data collection from human subjects.

\section{Results}

Figure 1 shows weekly CSD sales from all three food stores in Baddeck from January 1, 2013 to May 8, 2015. Pre-intervention, the pharmacy accounted for approximately $6 \%$ of total CSD sales (\$CAD) in Baddeck. The two peaks in the graph demonstrate two CSD sales peaks in the summer months (June, July and August) in 2013 and 2014. Table 1 shows descriptive statistics of weekly CSD sales from each store. For all stores, weekly CSD sales were significantly lower in non-peak weeks relative to summer peak weeks.

Table 2 shows the results from the two final ARIMA models. Baseline weekly average CSD sales were $\$ 3105.10$. Summer peak was significantly associated with higher weekly CSD sales at the community level. Model 1 illustrates that after controlling for summer peak, weekly CSD sales were $\$ 353.60$ (11.4\%) lower in the community as a whole in the post-intervention period $(p=0.39)$. Model 2 shows that after controlling for model-specified seasonality, weekly CSD sales were $\$ 663.10(21.4 \%)$ lower at the community level, postintervention $(p=0.13)$.

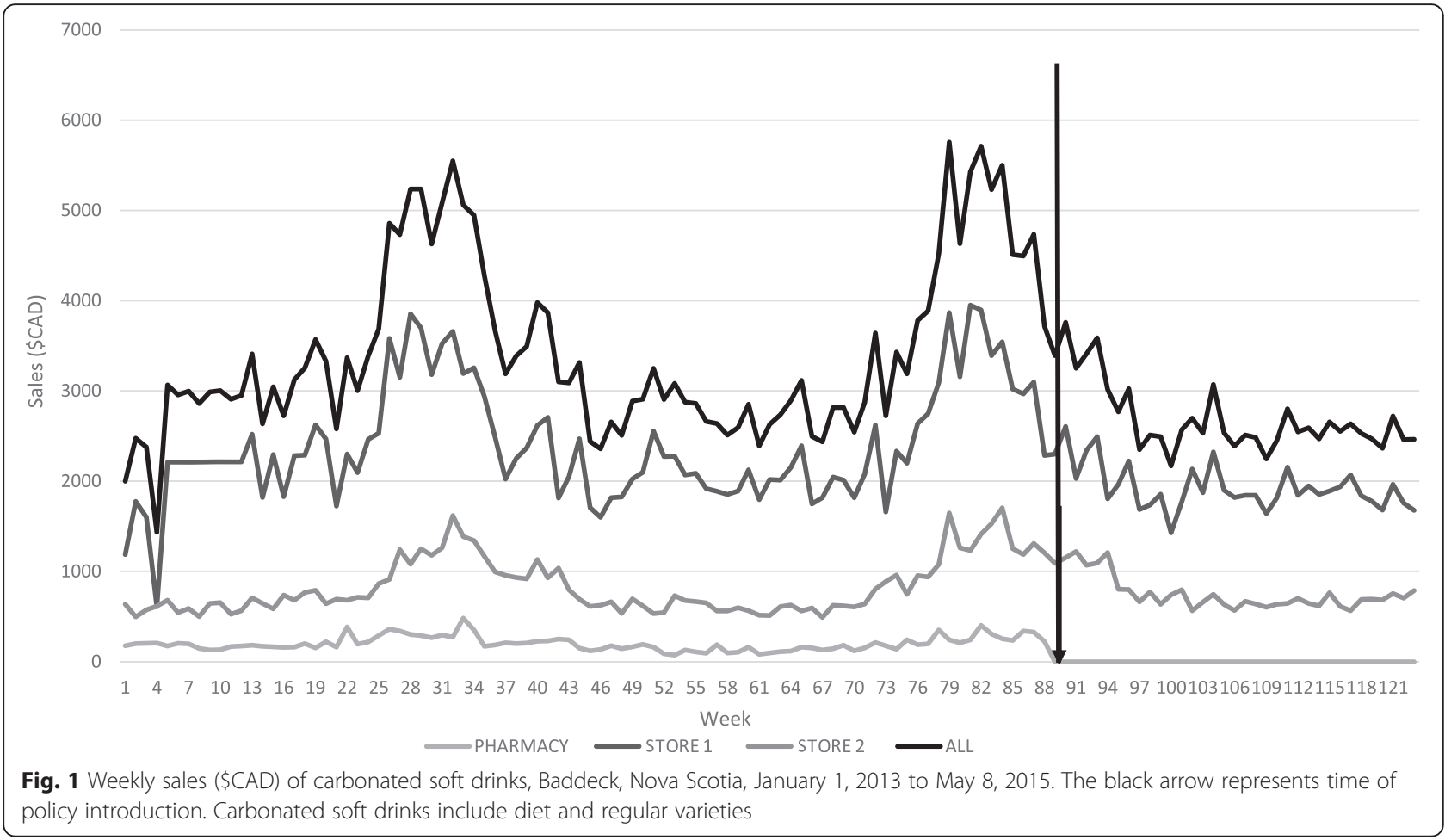


Table 1 Summary of weekly sales (\$CAD) of carbonated soft drinks in Baddeck, Nova Scotia, January 1, 2013 to May 8, 2015

\begin{tabular}{lllll}
\hline \multirow{2}{*}{ Store } & Weekly Sales & & & \\
\cline { 2 - 5 } & $\begin{array}{l}\text { Pre- policy mean } \\
(95 \% \mathrm{Cl})\end{array}$ & $\begin{array}{l}\text { Post- policy mean } \\
(95 \% \mathrm{Cl})\end{array}$ & $\begin{array}{l}\text { Non-peak months mean } \\
(95 \% \mathrm{Cl})\end{array}$ & $\begin{array}{l}\text { Summer peak months mean } \\
(95 \% \mathrm{Cl})\end{array}$ \\
\hline Pharmacy & $201.20(184.50,217.80)$ & 0.00 & $106.4(88.30,124.50)$ & $283.80(254.40,313.30)$ \\
Store 1 & $2401.40(2263.70,2539.1)$ & $1938.40(1851.60,2025.10)$ & $2025.50(1959.60,2091.30)$ & $3180.70(2971.80,3389.60)$ \\
Store 2 & $843.80(769.80,899.70)$ & $761.50(696.80,826.30)$ & $712.60(677.50,747.60)$ & $1192.00(1080.60,1303.50)$ \\
All stores & $3437.40(3231.6,3643.1)$ & $2699.90(2568.40,2831.30)$ & $2844.50(2756.30,2932.60)$ & $4656.60(4344.60,4968.50)$ \\
\hline
\end{tabular}

Carbonated soft drinks include diet and regular varieties

Table 3 shows the results from two ARIMA models (using Store 1 data and then Store 2 data) illustrating potential switching behaviours. No significant increase in CSD sales was observed in either of the stores.

\section{Discussion}

This study examined the impact of a restrictive RFE intervention on weekly CSD sales at the community level. The analysis contributes to the limited literature on impact of restrictive interventions. We found that after controlling for seasonal variations in CSD sales, a restrictive retailer-led intervention banning sales of CSD in a community pharmacy was associated with a nonsignificant decline in sales of CSD at the community level in Baddeck, Nova Scotia. Another key finding was that there was no evidence of "switching behaviour", that is, consumers did not buy more CSD from Store 1 or Store 2 after the pharmacy stopped selling CSD. This finding is meaningful from a population health intervention standpoint in particular, as it indicates that the pharmacy, rather than being a purposeful consumer destination for CSD purchasing, may actually have acted mainly as a source of impulse CSD purchasing within the community nutrition environment, as has been suggested previously [22].

Evidence on the impact of RFE interventions on diets and health has typically been generated by evaluations of permissive rather than restrictive interventions [16, 19]. Recent literature suggests mixed results of permissive interventions on healthy food purchasing $[16,25]$ and/or dietary intake [16, 17, 26]. While permissive interventions increase access to and availability of healthful options, such interventions may not be optimally effective without compatible efforts to restrict the availability of less healthy choices-producing an overall net food environment shift. This study contributes to the literature on restrictive RFE interventions, and finds a non-statistically significant impact of a pharmacy intervention in a small rural community.

Further research is required to analyze the myriad retail settings in which food and beverages are now sold. Industry analyses suggest that revenues of large chain pharmacies are split evenly between front-of store sales (e.g., foods and beverages, household items) and prescriptions, although smaller and independent pharmacies still generate most of their revenue through prescription sales [27]. The relatively minor proportion of revenue derived from the sale of sweet beverages at the study pharmacy facilitated the pharmacist's decision to remove them without risking significant declines in revenues. Pharmacies may have an improved capacity to accommodate restrictive interventions as part of their business model, and may therefore be ideal settings in which to test these interventions. To the extent that such interventions can be established as profitable-or at least not a major financial risk-it will increase the potential for scaling up implementation among other small, independent food retailers.

Community pharmacies are health care settings that have been identified as an important health promotion setting given their geographic accessibility, diverse

Table 2 Results from ARIMA models showing estimates of impacts of policy and summer peak or seasonality on weekly sales (\$CAD) of carbonated soft drinks in Baddeck, Nova Scotia, January 1, 2013 to May 8, 2015

\begin{tabular}{|c|c|c|c|c|}
\hline \multirow[t]{2}{*}{ Stores } & \multicolumn{2}{|c|}{ Model 1 (with summer peak) } & \multicolumn{2}{|c|}{ Model 2 (with ARIMA-specified seasonality) } \\
\hline & Estimate (SE) & $p$-value & Estimate (SE) & $p$-value \\
\hline \multicolumn{5}{|l|}{ All stores } \\
\hline Baseline level & $3105.1(192.6)$ & $<0.0001$ & $3105.1(192.6)$ & $<0.0001$ \\
\hline Policy & $-353.60(413.00)$ & 0.39 & $-663.10(439.50)$ & 0.13 \\
\hline Summer peak & $533.70(205.50)$ & 0.01 & & \\
\hline
\end{tabular}

Carbonated soft drinks include diet and regular varieties

ARIMA 110 model estimates 
Table 3 Results from ARIMA models showing estimates of impacts of policy on weekly sales (\$CAD) of carbonated soft drinks in Store 1 and Store 2 (non-intervention retailers), controlling for summer peak in Baddeck, Nova Scotia, January 1, 2013 to May 8, 2015

\begin{tabular}{lllllll}
\hline Stores & Store 1 & & & Store 2 & \\
\cline { 2 - 3 } \cline { 6 - 7 } & Estimate (SE) & $p$-value & & Estimate (SE) & $p$-value \\
\hline Policy & $21.40(343.90)$ & 0.95 & & $-115.80(133.20)$ & 0.39 \\
Summer peak & $488.40(205.50)$ & 0.005 & & $46.00(65.00)$ & 0.49 \\
\hline
\end{tabular}

customer base, and the high level of public confidence in pharmacists [28-31]. Programs that engage pharmacies as health promotion settings typically focus on community pharmacists' potential role as nutrition counsellors [29-32]. However, the dual roles of many pharmacists, first as health care professionals and second as business owners, can sometimes conflict. For example, the literature suggests that consumers [30] and nutritionists [31] perceive pharmacists who sell infant formula and bottles as having a conflict of interest in promoting breast-feeding. Consumers also perceive financial conflicts of interests when pharmacists recommend specific weight loss products they sell [29, 32]. Indeed, for community pharmacists, "both patient care and viability of the business need to be maintained" [32]. Therefore, interventions to promote healthy diets in pharmacies must also be economically feasible.

Financial conflicts of interest related to products sold at pharmacies are not new. Tobacco sales in pharmacies have spurred much debate over pharmacists' role as health care professionals, given that tobacco use continues to be the leading cause of preventable death in the world [33]. Nine of 10 Canadian provinces prohibit tobacco sales in pharmacies [34]. While sugar-sweetened beverages are not typically regarded as being as harmful as tobacco products, sugar-sweetened beverage consumption is harmful to health $[1,2]$. When CVS/Caremark announced it would stop selling tobacco in 2014, it did so based on carefully considered costs, including the normative and social costs of selling tobacco, which were high [34]. Future research should continue to monitor public opinion of sugar-sweetened beverages as a way of understanding normative and social risks for pharmacies that sell sugar sweetened beverages.

Several limitations of this study should be noted. First, we were unable to examine consumption phenomena at the individual/household level such as substitution effects. That is, we were unable to determine whether consumers who purchased less CSD ultimately increased their purchase of other types of beverages, including more or less nutritious beverages. Second, this analysis was also unable to distinguish between sales of diet and regular CSD. It is therefore unclear what proportion of the decline in sales of CSD was due to a reduction in sales of diet CSD. Industry analysis suggests that diet soft drinks have historically accounted for a small proportion of beverage sales [35]. It is therefore likely that observed declines were largely attributable to reductions in sales of sugar-sweetened CSD. Third, there was no control community in this natural experiment. The secular decline cited in industry documentation has not been as large as the declines observed in the current study, with total CSD sales volume declining approximately $3 \%$ over same time period in the study, since 2013 [35]. Further, most food environment intervention studies have used an uncontrolled pre-post design since the interventions are often outside of the researchers' control [19]. Finally, the sales data we obtained from the retailers did not include quantity of volume of CSD. This data limitation means that we were not able to detect the actual volume of CSD purchased. Considering tiered pricing strategies (i.e., CSD in larger-volume bottles cost less per ounce than CSD in smaller-volume bottles), if consumers switched to purchasing larger CSD bottles, our data would not reflect this phenomenon.

It is possible that people living in Baddeck would drive outside of their town to procure CSD. However, given that the nearest larger center is about an hour's drive away, and given that CSD were still available in both Store 1 and Store 2, it is unlikely that there was a change in out-of-town CSD procurement. Finally, it is likely that the lack of statistical significance accompanying the estimates was caused by the relatively short follow-up time ( $n=35$ weeks) and by the large standard errors reflected in large weekly variations in CSD sales. In addition, the relatively short follow-up time precluded an analysis of CSD during a summer peak in which the policy was in place, when a different type of consumer (namely tourists) would have comprised a greater proportion of people purchasing CSD.

Despite these limitations, this study was among the first to examine the impact of a restrictive RFE intervention on CSD sales at the community level. An important strength of this study is that objective weekly CSD sales data were obtained from all retail stores selling beverages in the study community over a 123 week period. The strength of the ARIMA model in addressing both autocorrelation in the data as well as seasonal variation in weekly CSD sales is also notable.

\section{Conclusions}

This is a promising area of inquiry that would benefit from research directions that engage complementary disciplinary expertise. For example, determining the level of public support for the pharmacy intervention would be a first step to understanding the feasibility and acceptability of this type of intervention. The financial 
impact of voluntary prohibitions on the sale of sugarsweetened beverages in pharmacies should also be examined. Finally, future research should further examine the extent to which declines in the sales of CSD translate into reduced CSD consumption at the individual/household level.

\section{Abbreviations}

RFE, ARIMA

\section{Acknowledgements}

We gratefully acknowledge the food retailers in Baddeck, Nova Scotia, who agreed to share their data for the purpose of this study.

\section{Funding}

LMM, NN, and SA acknowledge the support of the Canadian Cancer Society Research Institute [Major Program Grant \#701019] to the Propel Centre for Population Health Impact, which funded the study. CLM holds a Canadian Institute of Health Research Grant. DLO is supported by a Canadian Institutes of Health Research Fellowship. The study sponsor (Canadian Cancer Society Research Institute) had not role in study design, collection, analysis and interpretation of the data, writing the report, or the decision to submit this manuscript to BMC Public Health. GM is the community pharmacist whose removal of sugary beverages from his store is the intervention described in the current paper. GM owns an Atlantic Pharmasave pharmacy. GM facilitated data collection from the other food retailers in Baddeck and provided suggestions on earlier drafts of the manuscript.

\section{Availability of data and materials}

Data will not be shared because they are proprietary data owned by the participating food retail outlets in Baddeck, Nova Scotia, Canada.

\section{Authors' contributions}

LMM conceived of the study and drafted the manuscript and had full access to all aspects of the research and writing process. BEC and CLM provided substantial input into the conception and study design. GM participated in the study design and data collection. NN analysed the data. DLO, SA, BEC, CLM provided substantial feedback on preliminary drafts of this manuscript. All authors helped to interpret the data and edit the manuscripts. All authors approved the final version of the manuscript.

\section{Competing interests}

$L M M, N N, S A, C L M, B E C$, and DLO have no financial disclosures and no competing interests to declare. GM is employed by Atlantic Pharmasave.

\section{Consent for publication}

Not applicable.

\section{Ethics approval and consent to participate}

Institutional research ethics board approval was not sought for this study as it did not involve data collection from human subjects.

\footnotetext{
Author details

${ }^{1}$ Propel Centre for Population Health Impact, Faculty of Applied Health Sciences, University of Waterloo, 200 University Avenue West, Waterloo, ON N2L 3G1, Canada. ${ }^{2}$ Centre for Physical Activity and Nutrition Research, School of Exercise and Nutrition Sciences, Faculty of Health, Deakin University, Melbourne, Australia. ${ }^{3}$ Atlantic Pharmasave, 491 Chebucto St, Baddeck, NS BOE 1BO, Canada. ${ }^{4}$ Toronto Public Health, 277 Victoria Street, 5th Floor, Toronto, ON M5B 1W2, Canada. ${ }^{5}$ Community Health and Humanities, Faculty of Medicine, Memorial University of Newfoundland, 230 Elizabeth Ave, St. John's, NL A1B 3X9, Canada.
}

Received: 30 October 2015 Accepted: 7 July 2016 Published online: 16 July 2016

\section{References}

1. Malik VS, Popkin BM, Bray GA, Després J, Hu FB. Sugar-sweetened beverages, obesity, type 2 diabetes mellitus, and cardiovascular disease risk. Circulation [cited 24 June 2015]. 2010;121(11):1356-64.

2. Malik VS, Popkin BM, Bray GA, Després J, Willett WC, Hu FB. Sugar-sweetened beverages and risk of metabolic syndrome and type 2 diabetes: A meta-analysis. Diabetes Care [cited 24 June 2015]. 2010;33(11):2477-83.

3. Te Morenga LA, Howatson AJ, Jones RM, Mann J. Dietary sugars and cardiometabolic risk: Systematic review and meta-analyses of randomized controlled trials of the effects on blood pressure and lipids. Am J Clin Nutr [cited 24 June 2015]. 2014;100(1):65-79.

4. Singh GM, Micha R, Khatibzadeh S, Lim S, Ezzati M, Mozaffarian D. Estimated global, regional and national disease burdens related to sugar-sweetened beverage consumption in 2010. Circulation. 2015;132:639-66.

5. WHO calls on countries to reduce sugars intake among adults and children [homepage on the Internet]..2015. Available from: http://www.who.int/ mediacentre/news/releases/2015/sugar-guideline/en/.

6. Estimated calorie needs per day by age, gender, and physical activity level [homepage on the Internet]..2014. Available from: http://www.cnpp.usda. gov/sites/default/files/usda food_patterns/EstimatedCalorieNeeds PerDayTable.pdf

7. Public Health Agency of Canada. Curbing childhood obesity: A federal, provincial and territorial framework for action to promote healthy weights. Ottawa, Ontario: Public Health Agency of Canada; 2010.

8. Story M, Kaphingst KM, Robinson-O'Brien R, Glanz K. Creating healthy food and eating environments: Policy and environmental approaches. Annu Rev Public Health. 2008;29:253.

9. Giskes K, van Lenthe F, Avendano-Pabon M, Brug J. A systematic review of environmental factors and obesogenic dietary intakes among adults: Are we getting closer to understanding obesogenic environments? Obes Rev. 2011;12:e95-e106.

10. Minaker L. Measuring the food environment in canada. Ottawa, Ontario: Health Canada; 2013.

11. The Reinvestment Fund. Pennsylvania fresh food financing. 2011.

12. Kleinert S, Horton R. Rethinking and reframing obesity. Lancet. 2015;385(9985):13-9.

13. Food expenditures: Table 1, food and alcoholic beverages, total expenditures [homepage on the Internet]..2014. Available from: http://www. ers.usda.gov/data-products/food-expenditures.aspx.

14. Glanz K, Sallis JF, Saelens BE, Frank LD. Healthy nutrition environments: Concepts and measures. Am J Health Promot. 2005;19(5):330-3.

15. Sturm R, Hattori A. Diet and obesity in Los Angeles county 2007-2012: Is there a measurable effect of the 2008 "fast-food ban"? Soc Sci Med. [cited 24 June 2015]. 2015;133:205-11.

16. Gittelsohn J, Rowan M, Gadhoke P. Interventions in small food stores to change the food environment, improve diet, and reduce risk of chronic disease. Prev Chronic Dis. 2012;9:E59.

17. Escaron AL, Meinen AM, Nitzke SA, Martinez-Donate AP. Supermarket and grocery store-based interventions to promote healthful food choices and eating practices: A systematic review. Prev Chronic Dis [cited 5 February 2014]. 2013;10(4):1-20.

18. Kremers SPJ. Theory and practice in the study of influences on energy balance-related behaviors. Patient Educ Couns [cited 7 April 2016]. 2010;79(3):291-8.

19. Calancie L, Leeman J, Jilcott Pitts SB, Kettel Khan L, Fleischhacker S, Evenson $\mathrm{KR}$, et al. Nutrition-related policy and environmental strategies to prevent obesity in rural communities: A systematic review of the literature, 2002-2013. Prev Chronic Dis. 2015;12(E57):1-16.

20. Baddeck pharmacist pulls sugary drinks off shelves [homepage on the Internet]..2014 September 12, 2014. Available from: http://www.cbc.ca/ news/canada/nova-scotia/baddeck-pharmacist-pulls-sugary-drinks-offshelves-1.2764423.

21. N.S. Pharmacist bans sale of pop, other sugary drinks from his store [homepage on the Internet]..2014. Available from: http://www.ctvnews.ca/ canada/n-s-pharmacist-bans-sale-of-pop-other-sugary-drinks-from-his-store1.2005746 .

22. The Canadian soft drink industry [homepage on the Internet]. 2015. Available from: http://www.agr.gc.ca/eng/industry-markets-and-trade/ statistics-and-market-information/by-product-sector/processed-food-andbeverages/the-canadian-soft-drink-industry/?id=1172167862291. 
23. Baddeck pharmacy owner still feels good about decision to ban sugary drinks [homepage on the Internet]..2015 2015. Available from: http://www. capebretonpost.com/News/Local/2015-02-25/article-4056982/Baddeckpharmacy-owner-still-feels-good-about-decision-to-ban-sugary-drinks/1.

24. Yaffee R, McGee M. Introduction to time series analysis and forecasting. Amsterdam: Academic; 2000.

25. Lawman HG, Vander Veur S, Mallya G, McCoy TA, Wojtanowski A, Colby L, et al. Changes in quantity, spending, and nutritional characteristics of adult, adolescent and child urban corner store purchases after an environmental intervention. Prev Med [cited 25 June 2015]. 2015;74:81-5.

26. Cummins S, Flint E, Matthews SA. New neighborhood grocery store increased awareness of food access but did not alter dietary habits or obesity. Health Aff (Millwood). 2014;33(2):283-91.

27. Less drug, more Shoppers.[homepage on the Internet]..2013. Available from: http://www.canadianbusiness.com/companies-and-industries/less-drugmore-shoppers/.

28. Joyce AW, Sunderland VB, Burrows S, McManus A, Howat P, Maycock B. Community pharmacy's role in promoting healthy behaviours. J Pharm Pract Res [cited 23 June 2015]. 2007;37(1):42-4.

29. Fakih S, Marriott JL, Boardman H, Anderson C, Hussainy SY. Comparing women pharmacy consumers' experiences with weight loss treatment in victoria and nottingham: A cross-sectional study. BMC Public Health. [cited 19 June 2015]. 2014;14(1):662-73.

30. Maher JH, Hughes R, Anderson C, Lowe JB. An exploratory investigation amongst australian mothers regarding pharmacies and opportunities for nutrition promotion. Health Educ Res [cited 19 June 2015]. 2013:28(6):1040-50.

31. Maher JH, Lowe J, Hughes R. Community pharmacy as a setting for public health nutrition action: Australian nutritionists' perspectives. Public Health Nutr [cited 19 June 2015]. 2015;18(10):1864-72.

32. Um IS, Armour C, Krass I, Gill T, Chaar BB. Consumer perspectives about weight management services in a community pharmacy setting in NSW australia. Health Expect [cited 23 June 2015]. 2014;17(4):579-92.

33. $\mathrm{WHO}$ report on the global tobacco epidemic, 2013 [homepage on the Internet]..2013. Available from: http://apps.who.int/iris/bitstream/10665/ 85380/1/9789241505871_eng.pdf.

34. Richardson AJ. CVS/caremark: The costs and strategy of a tobacco free pharmacy. Accounting Perspectives. 2015;14(1):71-85.

35. Beverage Digest: Special Issue: U.S beverage results for 2014. [homepage on the Internet]. 2015. Available from: http://www.beverage-digest.com/pdf/ top-10_2014.pdf.

\section{Submit your next manuscript to BioMed Central and we will help you at every step:}

- We accept pre-submission inquiries

- Our selector tool helps you to find the most relevant journal

- We provide round the clock customer support

- Convenient online submission

- Thorough peer review

- Inclusion in PubMed and all major indexing services

- Maximum visibility for your research

Submit your manuscript at www.biomedcentral.com/submit
Biomed Central 